\title{
Astringency estimation of wines maturing in different types of containers
}

\author{
M. Basalekou ${ }^{1}$, C. Pappas ${ }^{2}$, P. Tarantilis ${ }^{2}$, M. Kyraleou ${ }^{1}$ V. Cotea ${ }^{3}$, and S. Kallithraka ${ }^{1, \text { a }}$ \\ ${ }^{1}$ Laboratory of Enology, Department of Food Science \& Human Nutrition, Agricultural University of Athens, 75 Iera Odos, 11855 \\ Athens, Greece \\ ${ }^{2}$ Laboratory of Chemistry, Department of Food Science \& Human Nutrition, Agricultural University of Athens, 75 Iera Odos, 11855 \\ Athens, Greece \\ ${ }^{3}$ University of Agricultural Sciences and Veterinary Medicine Iaşi, 3 M. Sadoveanu Alley, Iaşi, 700490, Romania
}

\begin{abstract}
Astringency is a parameter of great importance for wine quality. During wine maturation in wooden barrels it can be enhanced by tannins extracted by the wood. However, their concentration is not directly correlated with astringency. Mean Degree of Polymerization (mDP) is often employed to characterize the structural characteristics of tannins in wines, providing also information on their proanthocyanidin content. The prodelphinidin content $(\% \mathrm{P})$, as well as the percentage of epigallocatechin (EGC) in extension and terminal units, have been negatively linked with astringency. Since the intensity of astringency is a decisive factor for the quality of a barrel-aged wine in this experiment, the structural characteristics of wine proanthocyanidins were determined in four different Greek wines, two white (Vilana and Dafni) and two red (Kotsifali and Mandilari). All wines matured for nine months in different types of containers (stainless steel tanks and barrels made of different woods). The prodelphinidin (terminal or extension) content was determined by means of phloroglucinolysis, followed by HPLC-UV-MS analysis, while astringency was assessed by a panel of trained tasters. Multivariate analysis showed that only white wines that matured in Acacia barrels contained high \% $\mathrm{P}$ values independently of the variety used and were characterized as less astringent by the panel. Moreover, the determination of \%extension and terminal EGC units revealed that the tannins of the wines maturing in Acacia barrels, contain higher amounts of EGC as terminal units. These findings could be used by winemakers in order to select the appropriate type of barrel according to the type of wine.
\end{abstract}

Keywords: Astringency, proanthocyanidin, tannin, barrel

\section{Introduction}

Prediction of astringency is of great importance for winemakers as it would provide helpful information on a variety of tasks such as maceration and maturation length. Maturation in particular is a costly procedure that nowadays involves the use of new species of wood, some of which seem to not alter greatly the wine's final astringency, such as acacia, making them appealing for the maturation even of white wines (Alañón et al., 2018; Delia et al., 2017). The most reliable method for the estimation of astringency involves wine tasting from a trained panel; however, there have been efforts to overcome this necessity through the establishment of analytical methods. Most of these methods deal with the quantification of chemical compounds linked to the astringency sensation, like phenolic compounds and more specifically tannins (Ma et al., 2014). However, astringency is not elicited by one single compound; it can be either enhanced or suppressed by the presence of other compounds such as acids and anthocyanins that do not directly contribute to its perception (Brossaud et al., 2001). One of the indirect methods implemented for the estimation of

a e-mail: stamatina@aua.gr astringency involves the determination of the mean Degree of Polymerization of tannins (Chira, Jourdes et al., 2012). The mDP provides information on the type of tannins (mainly on their average size and structural composition) present in a wine, as it estimates their proanthocyanidin content after acid catalysis with phloroglucinol. This way, the terminal tannin units are released as flavanol monomers and the extension units form adducts with phloroglucinol. Wine tannin polymers mostly consist of $(+)$-catechin $(\mathrm{C})$, (-)-epicatechin (EC), (-)-epigallocatechin (EGC) and (-)epicatechin gallate (ECG) subunits (Benaiges \& Guillén, 2007). Tannin average size determined by this method correlated with astringency of Cabernet Sauvignon wines form Pauillac denomination. However, in the case of Greek wines mDP seems not to significantly correlate with astringency, probably due to the shorter type of tannins (Petropoulos, et al., 2017). The prodelphinidin content $(\% \mathrm{P})$ which is the percentage of extension and terminal (-)-epigallocatechin (EGC) subunits has been documented in literature to negatively correlate with the perceived astringency (Ferrer-gallego et al., 2015; Kyraleou et al., 2016).

The aim of this study was to determine the contents of (-) epigallocatechin in wines (both red and white) matured

(C) The Authors, published by EDP Sciences. This is an Open Access article distributed under the terms of the Creative Commons Attribution License 4.0 (http://creativecommons.org/licenses/by/4.0/). 
in different barrel woods, and examine its potential use as a marker of astringency estimation during maturation.

\section{Materials and methods}

\subsection{Wines and wood maturations}

The wines used in this experiment originated from the region of Heraklion in Crete, Greece and were chosen for their different tannic content. Vilana and Dafni are white varieties while Kotsifali and Mandilari are red. The barrels used were also selected accordingly, i.e. to present differences in the amount of extractable phenols. For this reason, barrels (2251) with a medium toast made of French and American oak, Acacia and Chestnut were selected. In addition, for comparison reasons, stainless steel tanks with or without immersion of French oak sticks were used. French and American barrels (2251) were purchased from 'Tonnellerie du Monde World Cooperage', Acacia barrels from 'Tonnellerie du sud ouest' and Chestnut barrels from Tsias Metsovo. French oak sticks were Oenostick @V18 from Seguin Moreau ( $7 \mathrm{~g}$ of oak sticks per liter of wine). All wines were transfered to the barrels or tanks after completing fermentation in stainless steel tanks. Samples from each container were used for analyses every three months for a period of nine months.

\subsection{Proanthocyanidin composition}

In order to determine the proanthocyanidin composition, phloroglucinolysis was performed according to the method described by Chira et al., (2012). Flavanon units and adducts released by phloroglucinolysis were analyzed by a Shimadzu 2010A LC/MS from Shimadzu corporation, according to the method described by Kyraleou et al., (2015). All flavanols, either terminal or extension (phloroglucinol adducts) subunits were expressed as moles. Percentage of prodelphinidins $(\% \mathrm{P})$ was expressed as: $100 \times($ SUM of terminal and extension EGC subunits / SUM of all terminal subunits).

\subsection{Sensory analysis}

Astringency was assessed by a trained panel. Eleven winemakers participated in eight sessions where they were trained on the astringency perception according to the method described by Chira et al., (2012). Different concentrations of aluminum sulfate were prepared for the astringency intensity training. All samples were evaluated twice and red and white wines were assessed in different tasting sessions.

\subsection{Statistical Analysis}

For proanthocyanidin composition results and sensory analysis data, mean values and standard error were calculated. Analysis of variance (ANOVA) was performed, using Tukey's comparison tests when samples were significantly different $(p<0.05)$.

\section{Results and discussion}

\subsection{Sensory analysis}

As it is shown in Fig. 1, the different containers used in this experiment for red wines did not result in perceived

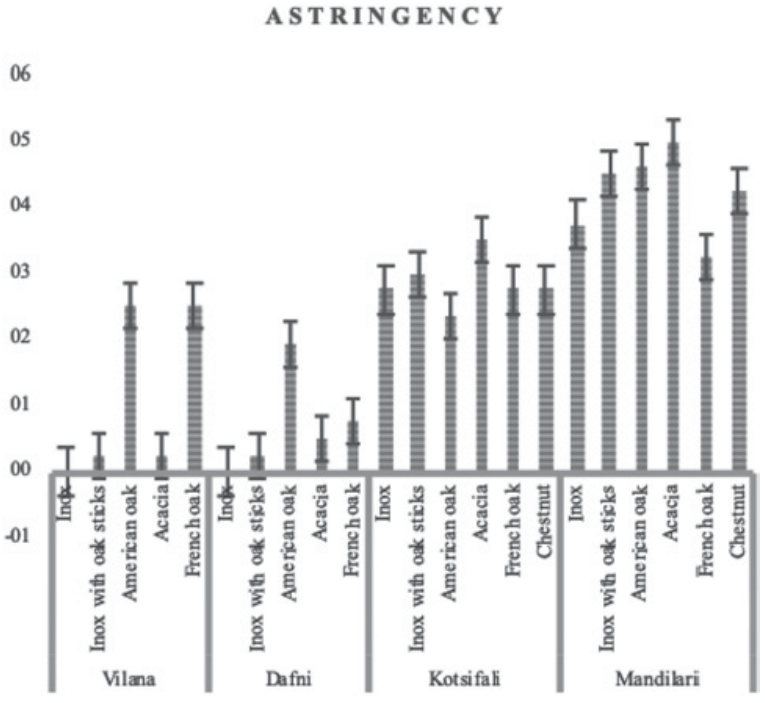

Figure 1. Astringency intensity for wines after 9 months of maturation in different containers.

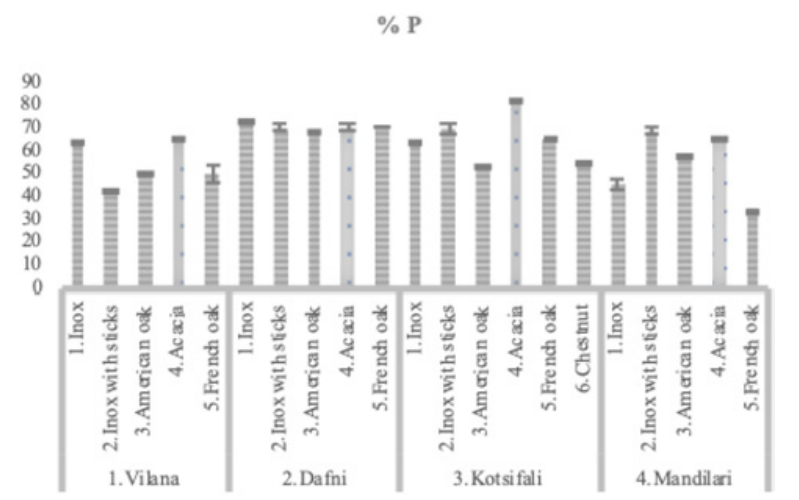

Figure 2. Prodelphinidin content of wines after nine months of maturation.

astringency differences. Probably astringency of red wines was already high and any further increase or decrease could not be easily detected by the panel. However, for the white varieties of the experiment, Acacia wood container resulted in less enhancement of their perceived astringency (Fig. 1).

\subsection{Proanthocyanidin composition}

Analysis of the proanthocyanidin composition of the wine samples showed that wines of Acacia barrels have higher contents of prodelphinidins compared to the wines aged in the other barrels of the experiment. The highest value of prodelphinidins was observed in wines from Kotsifali variety (Fig. 2).

Moreover, regardless of the grape variety used, Acacia barrels showed higher levels of EGC as terminal units (Fig. 3).

\section{Conclusions}

The proanthocyanidin subunit composition differed among the wines matured at different wood containers. The storage of white wines in Acacia barrels did not result in astringency enhancement even when the wines were in contact with the wood for longer contact periods (9 months). This finding could provide winemakers with 


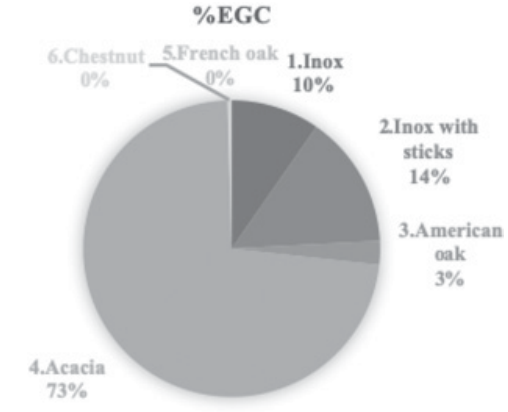

Figure 3. (-)-Epigallocatechin percent (\%EGC) as terminal units of wines after nine months of maturation.

a useful tool when deciding how long but also in what type of barrel wood to mature a wine, red or white.

\section{References}

M.E. Alañón, L. Marchante, M. Alarcón, I.J. DíazMaroto, S. Pérez-Coello, M.C. Díaz-Maroto, J. Sci. Food and Agriculture 98, 5795 (2018) https://doi.org/10.1002/jsfa.9129

A. Benaiges, P. Guillén, 8.5. Botanical Extracts. In Analysis of Cosmetic Products (Elsevier, 2007) p. 345 https:// doi.org/10.1016/B978-044452260-3/50044-9

F. Brossaud, V. Cheynier, A.C. Noble, Aust. J. Grape and Wine Res. 7, 33 (2001) https:// doi.org/10.1111/j.1755-0238.2001.tb00191.x
K. Chira, M. Jourdes, P.L. Teissedre, Eur. Food Res. Technol. 234, 253 (2012) https://doi.org/ 10.1007/s00217-011-1627-1

L. Delia, A.M. Jordão, J.M. Ricardo-da-silva, Influence of Different Wood Chips Species (Oak , Acacia and Cherry) Used in a Short Period of Aging on the Quality of 'Encruzado' White Wines. MITT EILUNGEN KLOSTERNEUBURG 67, 84 (2017)

R. Ferrer-gallego, N. Quijada-morín, N.F. Brás, P. Gomes, V. Freitas, J.C. De, Rivas-gonzalo, M.T. Escribano-bailón, Characterization of Sensory Properties of Flavanols-A Molecular Dynamic Approach, $381 \quad$ (2015) https://doi.org/10.1093/chemse/bjv018

M. Kyraleou, S. Kallithraka, S. Koundouras, K. Chira, S. Haroutounian, H. Spinthiropoulou, Y. Kotseridis, J. Int. Des Sciences de La Vigne et Du Vin 49, 71 (2015) https://doi.org/10.20870/oeno-one.2015.49. 2.92

M. Kyraleou, S. Koundouras, S. Kallithraka, N. Theodorou, N. Proxenia, Y. Kotseridis, J. Sci. Food Agric. 96, 988 (2016) https://doi.org/10.1002/jsfa.7175

W. Ma, A. Guo, Y. Zhang, H. Wang, Y. Liu, Trends in Food Sci. Technol. 40, 6 (2014) https://doi.org/10.1016/j.tifs.2014.08.001

S. Petropoulos, A. Kanellopoulou, I. Paraskevopoulos, Y. Kotseridis, S. Kallithraka, J. Food Compos. Anal. 63, 98 (2017) https://doi.org/10.1016/j.jfca.2017.07.038 